\title{
A SURVEY ON THE ACOUSTICAL CONDITIONS IN A SPANISH SECONDARY SCHOOL
}

\author{
A. GARCÍA, J. ROMERO*, A.M. GARCÍA* and L.J. FAUS* \\ Laboratory of Acoustics, Applied Physics Department, Av. Dr. Moliner 50, SP-46100 Burjassot \\ (Valencia), Spain \\ *University of Valencia, Valencia, Spain
}

\begin{abstract}
RESUME. Cette communication donne une détaille information sur les conditions acoustiques d'une école de baccalauréat de Gandia (Espagne). Les niveaux de bruit, les temps de réverbération et les coefficients d'intelligibilité on été measurés in différent salles de classe. Les opinions des professeurs et etudiants sur les conditions acoustiques de cette batiment scolaire ont été aussi évalués.
\end{abstract}

\begin{abstract}
The present paper reports on a study of the acoustical conditions in a secondary school of Gandia (Spain). Our data include a complete information on noise levels, reverberation times and speech intelligibility of classrooms, together with the results of two social surveys adressed to teachers and students in order to know their attitudes towards this problem.
\end{abstract}

\section{INTRODUCTION}

The schools are established to promote learning, which is acquired largely by voice and listening. Therefore, acoustics is one of the most important physical properties that determine how well the school buildings can serve their primary function (1).

During the last decades some effort has been devoted to determine the effects of envixonmental noise on schools $(2)(3)(4)$. Most of these investigations are based in the subjective responses given by the teachers to a specific questionnaire. A number of these studies have also indicated that excesive noise can influence the speech intelligibility, performance and even behaviour of school students.

The present communication reports on a pilot survey, carried out in a secondary school of Gandia (Spain), and includes the data obtained in detailed acoustical measurements, together with the results of two social surveys adressed to teachers and students in order to know their attitudes to this problem.

\section{ACOUSTICAL MEASUREMENTS}

The Institute Ausias March is one of the three secondary schools 
of Gandia, a medium size city located about $60 \mathrm{~km}$ south of valencia (spain). The two floor building was constructed about 1930 and it is situated in the city centre. This school consists of 28 classrooms and laboratories of small and medium capacity, one general purpose lecture room, one recreation courtyard, one professors room and a number of offices, stores and service rooms. At the present, there are about 60 professors and 800 students in this school.

Noise levels have been measured along several consecutive days in five different points of the school. Three locations correspond to the external facades of the building (two streets and one corner), with quite intense road traffic. The two other measurement points were situated in an internal corridor and in the open air recreation courtyard. All these measurements were carried out using a $1 / 2$ inch condenser microphone (BK4165), a noise level analyzer (BK4426) and an alphanumeric printer (BK2312). The hourly values of L1, L10, L50, L90, L99 and Leq have been obtained in all cases.

The noise levels measured in external facades show the typical day variations found out in many noise surveys (5). For instance, the values of equivalent sound levels Leq measured in the most exposed facade range from 50-55 dBA (during night) to 70-75 dBA (during day). The values of Leg measured during the activity period in the internal corridor and in the recreation courtyard of the school are about 72-76 $d B A$ and 65-70 dBA, respectively.

In the classrooms facing to the noisiest street internal noise levels are about $55 \mathrm{dBA}$ (windows closed) and $65 \mathrm{dBA}$ (windows open), far away from the acceptable level of 40 dBA. The average noise insulation of the building facades is about 20 dBA. Average noise insulation of walls between adjacent rooms is about 30-35 dBA.

The reverberation times $R T$ have been measured in some typical classrooms using a sound power source (BK4205), a precision sound level meter (BK2230) with octave filter (BK1625) and a portable level recorder (BK2306). Obviously, the values obtained depend of room size, furniture and finish of walls and ceiling. For instance, in an empty classroom of about 200 cubic meters, the reverberation time is 2.1 seconds at a frequency of $1000 \mathrm{~Hz}$.

Finally, a number of measurements of speech intelligibility, (using the method of rapid speech transmission index or RASTI) (6), have been carried out in ten different classrooms. For unoccupied classrooms, RASTI values range from 0.40 to 0.45 . For occupied classrooms in actual working conditions (from 15 to 40 students depending of room size), RASTI values range from 0.57 to 0.67 .

\section{SOCIAL SURVEY (TEACHERS)}

A total of 33 teachers have completed the questionnaires ( $55 \%$ of total). The respondents were male $(61 \%)$ and female (39\%), with a wide age range: from 20-30 years (16\%), 30-40 years $(42 \%), 40-50$ years $(32 \%)$ and older than 50 years $(10 \%)$. About $30 \%$ of respondents are teaching less than 10 years and $70 \%$ more than 10 years.

A five point semantic scale has been used to rate the subjective evaluation of the classrooms conditions (in a general sense). About $28 \%$ of interviewed teachers declare that these conditions are "very good" or "good", 40\% "fair" and 32\% "bad" or "very bad". The opinions about a number of specific conditions of the classrooms are quite positive in general. However, the classroom noise background deserves 
a most negative evaluation: about $85 \%$ of the respondents consider that the classrooms where they are teaching are "noisy".

According to the teachers, the noise perceived in the classrooms is originated mainly outside the classrooms (76\% of responses). Road traffic is the most annoying noise source: about $32 \%$ of the total sample declare to be "very much annoyed" by traffic noise, $36 \%$ "rather annoyed", 28\% "moderately annoyed" and only 4\% "little" or "not at all annoyed". Another quite disturbing noise sources are the students in the own classrooms, the school courtyard and the adjacent classrooms (in this order).

Most of the respondents declare that environmental conditions of educational centers are an important factor of their work. All of them know are conscious that this building is not sound insulated. They experience that noise is much more disturbing at the end of the academic course (April/June), when classroom windows are usually open. Related to this point, many teachers declare that they keep windows closed in warm weather to reduce the outside noise immission. on the other hand, the practice of raising the voice to overcome noise seems to have a high cost: about $26 \%$ of teachers declare to suffer "often" some throat disease (aphonia, hoarseness, etc.).

Most of teachers consider that noise disturbs significantly (two upper steps in a five step scale) the attention of students (89\%), interferes the communication teacher-students $(92 \%)$, produces an additional stress in the teachers $(88 \%)$ and make nervous to the students (76\%); absolutely all respondents opine that noise is a negative factor of educational process (100\%).

\section{SOCIAL SURVEY (STUDENTS)}

A total of 602 students have completed the questionnaires ( $75 \%$ of total). The respondents were male (44\%) and Eemale (56\%) from 14 to 19 years old, attending to four different teaching levels.

Above all, the analysis of responses shows that the general evaluation of the classroom conditions is more positive for students than for teachers. About $50 \%$ of the students opine that classroom conditions are "very good" or "good", 34\% "fair" and 16\% "bad" or "very bad". In coincidence with teachers, most of students consider that the classrooms of this school are spacious, tidy, pleasant, Iuminous, etc. They coincide also in that noise is the most negative feature of classrooms ( $66 \%$ of responses).

Regarding to the origin of noise perceived in classrooms, the coincidence with the teacher responses is almost perfect: about $74 \%$ of students opine that noise is mainly generated outside the own classrooms. Although the students coincide in that road traffic noise is a very important noise source, the corresponding annoyance seems to be lower than experienced by teachers. In addition, the responses of the students reveal that the disturbance produced by the noise originated by the own students inside or outside the classrooms is also lower.

Not surprisingly, the criticism of students about noise effects is not as strong as teachers. However, they consider also that noise disturbs their attention (61\%), interferes the communication (75\%) and make them nervous (45\%); about $73 \%$ of students opine that noise is a "very" or "rather" negative factor of educational process.

Most probably, the differences in the responses of teachers and 
students are related to a difeerent general sensitivity towards noise in general in these two population groups. In the answers to a direct question on this subject, about $23 \%$ of teachers declare to be "very much" sensitive to noise, $62 \%$ "rather", $11 \%$ "moderately", 4\% "Iittle" and $0 \%$ "not at all". The corresponding percentages for students are $7 \%, 29 \%, 40 \%, 19 \%$ and $5 \%$, respectively.

The hearing sensitivity of a reduced sample of students $(n=20)$ has been also measured using a Maico A40 audiometer. Mean hearing loss of this group is $19 \mathrm{~dB}$ for $500 \mathrm{~Hz}, 9 \mathrm{~dB}$ for $1000 \mathrm{~Hz}, 4$ dB for $2000 \mathrm{~Hz}$ and $8 \mathrm{~dB}$ for $4000 \mathrm{~Hz}$; in some particular cases, the observed hearing losses are astonishingly high. Although the sample is too reduced to be conclusive about the real causes of such hearing losses, it should be mentioned that $90 \%$ of students assist "often" to discos, pubs or pop concerts, $60 \%$ drive "often" a motorcycle and $20 \%$ uses "often" earphones to hear music. More work on this important subject is now in progress.

\section{CONCLUSIONS}

The results obtained in a series of physical measurements (noise levels, reverberation times and speech intelligibility) and in two social surveys (teachers and students), carried out in a secondary school of Gandia (Spain), have revealed that the acoustical general conditions of this school are quite deficient and, in some cases, they are clearly unnaceptable. There are reasons to believe that the excesive noise and reverberation of the classrooms are very negative factors for the educational activities of this center.

\section{REFERENCES}

(1) V.O.knudsen and C.M.Harris. "Acoustical designing in architecture" Acoustical Society of America (1978).

(2) M.A.Crook and F.J.Langdon. "The effects of aircraft noise in schools around London airport". Journal of Sound and Vibration. 34221 (1974)

(3) J.W.Sargent, M.I.Gidman, M.A.Humphreys and W.A.Utley.- "The disturbance caused to school teachers by noise". Journal of sound and vibration 70557 (1980).

(4) J.s.Bradley. "speech intelligibility studies in classrooms". J.Acoust.SOC.Am. 80846 (1986).

(5) A.Garcia and L.J.Faus. "Statistical analysis of urban noise levels". Ler Congrès Français d'Acoustique. C2-281. Lyon (1990).

(6) T.Houtgast and H.J.M.Steeneken. "The modulation transfer function in room acoustics as a predictor of speech intelligibility" Acustica $2866(1973)$. 